\title{
Evidence for highly depleted lower continental crust using an integrated microanalytical reconstitution approach
}

\author{
Robert Emo and Balz Kamber
}

School of Earth and Atmospheric Sciences, Queensland University of Technology, United States

Accurately constraining the composition of the continental crust is essential for understanding Earth's geological evolution. However, due to the difficulty of accessing the deep crust, the composition of the lower crust is poorly constrained. This includes the heat-producing elements (HPE), Th, U and K, which are vital for investigating Earth's thermal history. Chemical estimates of the lower crust are based on the geochemical analysis of tectonically-exhumed terrains and rare granulite xenoliths brought to the surface by explosive volcanism [1]. The databases used to create such estimates rely heavily on conventional bulk rock analysis of granulite xenoliths. However, many xenoliths are too small to be analysed with this method, creating a potential bias towards larger samples, and the effect of host magma contamination and secondary alteration could go undetected when the whole rock is homogenised to a powder. In this study, an integrated microanalytical approach is used to investigate the potential effects of secondary processes and reconstruct the primary compositions of granulite xenoliths from central Queensland, Australia.

Mineral phase maps were obtained by SEM-EDS using a TESCAN Integrated Mineral Analyzer (TIMA) field emission SEM to quantify the xenoliths' modal mineralogies (Figure 1). Elemental maps show that $\mathrm{K}$ is enriched in fractures, grain boundaries and secondary glass phases, and relatively low in the primary rock-forming minerals. Each xenolith sample's modal mineralogy was combined with in situ quantitative chemical analysis of each mineral phase by electron probe micro-analysis (EPMA) for major elements and laser-ablation inductively-coupled-plasma mass spectrometry (LA-ICP-MS) for trace elements. These analyses confirm that the primary minerals in the xenoliths are depleted in the HPE and other incompatible trace elements. High spatial resolution (10 $\mu \mathrm{m}$ beam width) LA-ICP-MS rasters show that highly incompatible elements are concentrated in grain boundaries, whereas diffusion into the rock-forming minerals was minimal (Figure 2). A comparison of trace element ratios of the reconstructed xenoliths and the host basalts reveals that magma infiltration was the likely cause of HPE enrichment along grain boundaries. While the degree of infiltration in the xenoliths varies, at least some contamination is found in all xenoliths thus far investigated, and large xenoliths can be as affected as smaller ones.

The reconstituted primary compositions of the Queensland granulite xenoliths show that the lower crust in this area is extremely depleted in highly incompatible trace elements. Compared to global granulite xenolith data, the investigated xenoliths represent some of the most refractory lower crust thus far investigated. Using this reconstitution approach can significantly expand the granulite xenolith geochemical database, and correcting for host rock contamination effects may reveal highly depleted lower crust in other regions. 


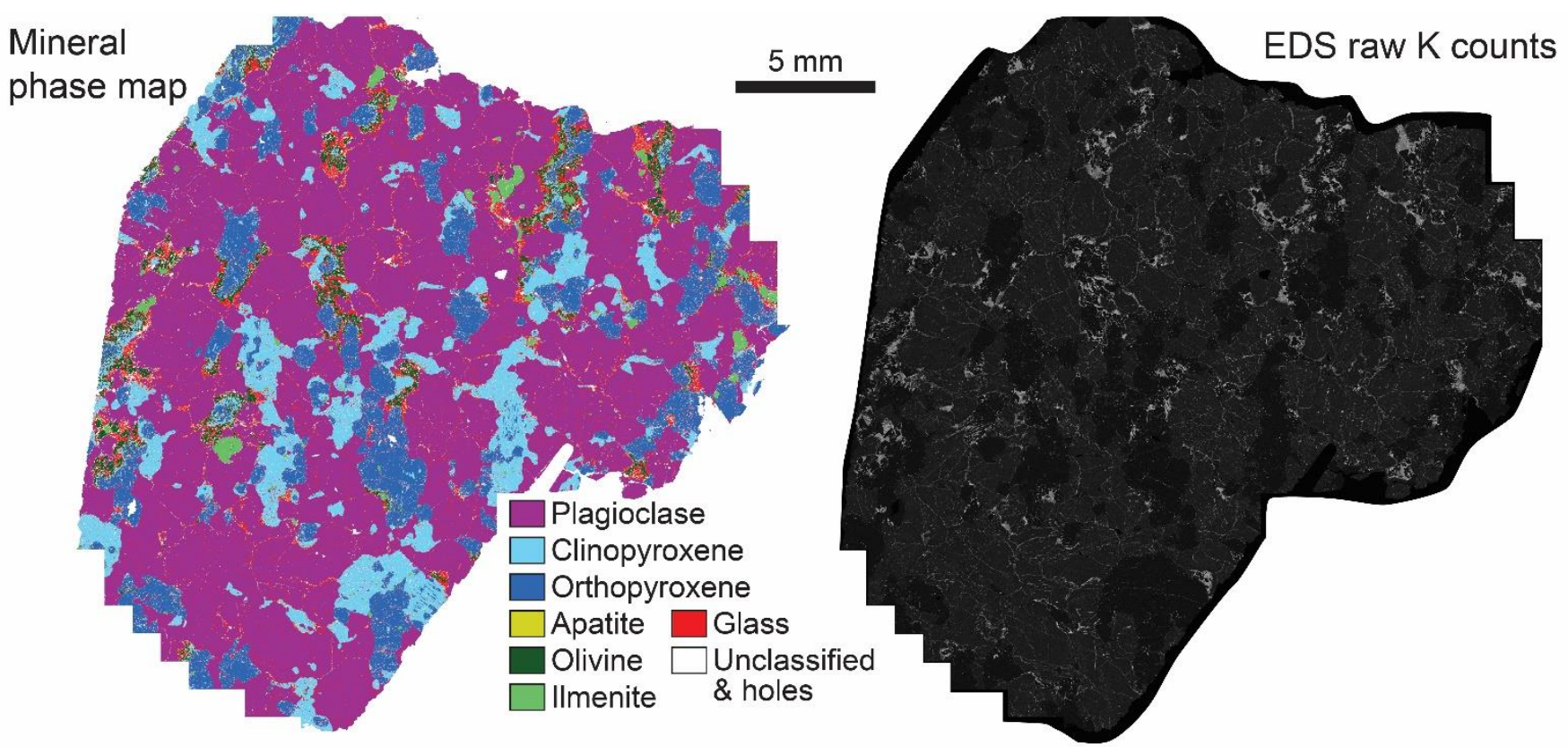

Figure 1. An example of a mineral phase map and the raw K count map of a lower crustal xenolith from central Queensland, obtained by SEM-EDS mapping.
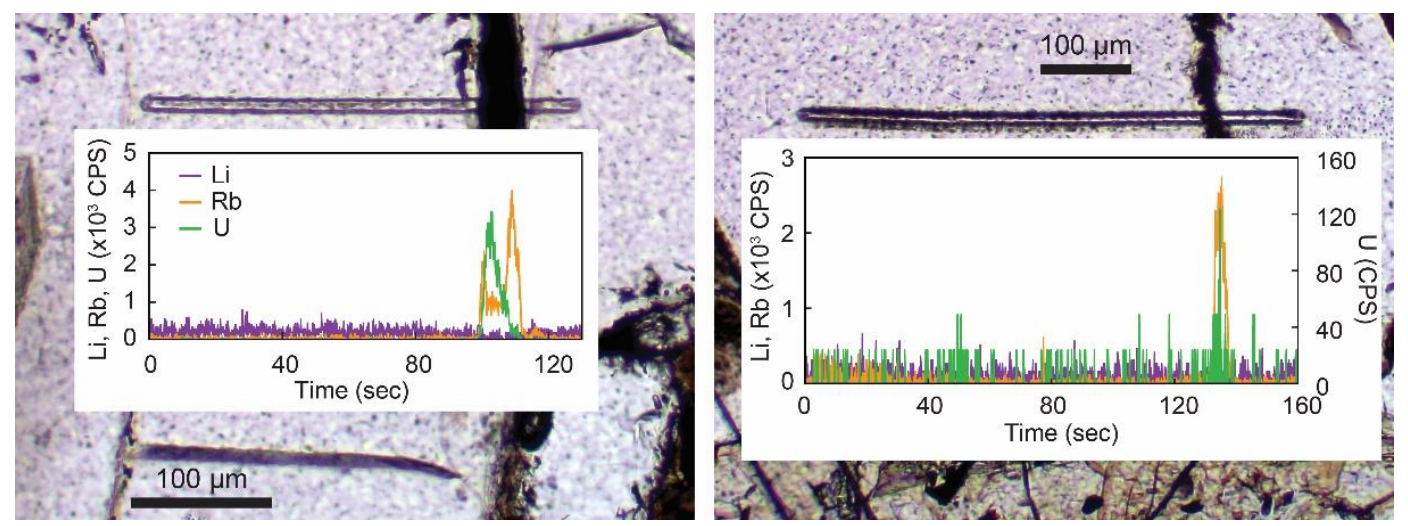

Figure 2. High spatial resolution trace element rasters of baseline-subtracted counts per second (CPS) of primary mineral phases and grain boundaries in a Queensland lower crustal xenolith, obtained by LAICP-MS.

\section{Reference}

[1] Rudnick R. L. and Gao S. (2003) Composition of the Continental Crust. In Treatise on Geochemistry (eds. H. D. Holland and K. K. Turekian). Pergamon, Oxford. pp. 1-64. 